\title{
Particle Stability During Pressurized Intra-peritoneal Aerosol Chemotherapy (PIPAC)
}

\author{
AGATA MIKOLAJCZYK ${ }^{1}$, VERIA KHOSRAWIPOUR ${ }^{2}$, JUSTYNA SCHUBERT ${ }^{3}$, \\ HARIS CHAUDHRY ${ }^{4}$, ALESSIO PIGAZZI ${ }^{4}$ and TANJA KHOSRAWIPOUR ${ }^{4}$ \\ ${ }^{1}$ Department of Biochemistry and Molecular Biology, Faculty of Veterinary Sciences, \\ Wroclaw University of Environmental and Life Sciences, Wroclaw, Poland; \\ ${ }^{2}$ Department of Orthopedic and Trauma Surgery, Ortho-Klinik Dortmund, Dortmund, Germany; \\ ${ }^{3}$ Department of Food Hygiene and Consumer Health Protection, \\ Wroclaw University of Environmental and Life Sciences, Wroclaw, Poland; \\ ${ }^{4}$ Division of Colorectal Surgery, Department of Surgery, University of California, Irvine, CA, U.S.A.
}

\begin{abstract}
Background/Aim: Pressurized intra-peritoneal aerosol chemotherapy (PIPAC) is a new approach in the treatment of peritoneal carcinomatosis. With PIPAC currently limited to liquid chemotherapeutic solutions, this study aims to investigate whether the application range may be extended to the delivery of therapeutic nano- or microparticles. Materials and Methods: Human serum, bacteria cultures and macrophage cells were aerosolized in an established ex vivo model. Human serum composition was analyzed via gel electrophoresis. The viability of bacteria and macrophage cells was measured prior to and following PIPAC. Results: No structural disintegration of the plasma solution was detected. While the concentration and viability of Escherichia coli and Salmonella Enteritidis did not significantly change following aerosol formation, macrophage cells showed structural disintegration. Conclusion: Our ex vivo data suggest that PIPAC can be used to deliver complex particles. The delivery of small and less complex particles was feasible, yet the mechanical and physical properties of PIPAC might alter the stability of larger and more complex particles.
\end{abstract}

As the survival benefit of intraperitoneal chemotherapy (IPC) in peritoneal metastasis (PM) has been shown a decade ago, this field has since been intensively studied, resulting in new developments in treatment and drug application. Despite these efforts, the overall prognosis of patients with PM still

Correspondence to: Tanja Khosrawipour, Division of Colorectal Surgery, Department of Surgery, University of California Irvine (UCI), CA, U.S.A. Tel: +1 7144565443, e-mail: tkhosrawipour@gmail.com

Key Words: Ex vivo, particle disintegration, pressurized intraperitoneal aerosol chemotherapy (PIPAC), peritoneal metastasis, nanoparticles. remains poor with low-median survival rates (1). This is partially due to major limitations exhibited in current treatment regimens. While IPC is an important therapeutic option, it has significant shortcomings such as high local complication rates with regards to its application devices, heterogeneous intraperitoneal drug distribution and limited tissue penetration rates. The main precondition for a possible curative approach is the complete macroscopic surgical cytoreduction preceding IPC, since the antitumor effect of IPC is strongly limited by poor penetration $(<1 \mathrm{~mm})$ of anticancer drugs into peritoneal nodules $(2,3)$. The restricted diffusion of IPC is attributed to the peritoneum-tumor barrier (4), a high interstitial tumor pressure (5) and the effect of the capillary network, which drains drugs out of the tumor tissue. Pressurized intra-peritoneal aerosol chemotherapy (PIPAC) has been introduced as a new treatment option with the potential to overcome the technical and biological limitations of liquid solutions like high distribution inhomogeneity and limited tissue penetration (6). Using an aerosol-creating device, the drug containing solution is delivered into the abdominal cavity in a $12-\mathrm{mmHg}$ "therapeutic capnoperitoneum" in the shape of micro droplets. In vivo animal experiments report uniform drug distribution in the abdominal cavity since the aerosol droplets are assumed to behave "gas-like" (6). However, until today, PIPAC has always been performed with liquid chemosolutions using doxorubicin, cisplatin or oxaliplatin in a preclinical or a clinical setting and compared with IPC. Clinical results are encouraging for liquid chemosolutions (7, 9). The application of larger and more complex particles offers an opportunity to investigate how current IPC qualities may be improved with regards to efficiency and tumor toxicity. The size of the particles impacts the clearance pathway since larger particles exhibit longer resistance time in the peritoneum. Thus, larger particles are likely to show a 
higher contact time with the metastatic surface. The releasing mechanism, degradation and diffusion time can be modified by carrier materials. Basic understanding of technical (10$12)$, biological $(13,14)$ and applicational (15-17) principles has been established for PIPAC. At this point, it is important to evaluate whether the use of PIPAC can be extended to the application of higher and more complex elements such as nano- and microparticles. Some of these particles have been intensively studied for both intraperitoneal and intravenous delivery. Among this wide range of particles are protein particles like antibodies (18), more complex functional elements like liposomes (19), tumor penetrating microparticles (20), and even activated macrophages (21). Some of these complex particles have been studied in clinical practice (19-21) for IPC. Theoretically, a high local concentration of target particles covering the peritoneal surface could be reached via PIPAC using only a low volume of specific drugs. However, the mechanical stress created by the outburst of pressurized aerosol particles might destroy or disintegrate the particles and cell structures and therefore disqualify PIPAC as a technology for more complex particles. With respect to these considerations we aimed to analyze whether the stability of more complex particles is ensured following PIPAC application. For this purpose, PIPAC was performed with different solutions containing greater sized particles and structures which show increased sensitivity to mechanical stress. The first solution used was commercially available human serum (H4522, SigmaAldrich, St. Louis, USA) containing a wide range of different sized proteins ranging from $10 \mathrm{kDa}$ to $180 \mathrm{kDa}$. The second and third solution used contained two different types of bacteria: Escherichia coli and Salmonella Enteritidis in a Luria-Bertani (LB) broth. The forth solution used was a nutrient solution with macrophages. Particle stability was measured by means of electrophoresis, bacterial and macrophage survival rate. The wide range of particle sizes investigated in this study ranging from smaller proteins of $10 \mathrm{kDa}$ to macrophages with sizes of up to $5 \mu \mathrm{m}$ likely allows to determine the limits of PIPAC. The use of larger particles $>5 \mu \mathrm{m}$ is critical as these might destroy the microcatheter. Moreover, physical considerations of the gravitational effect advise against the use of larger sized particles for PIPAC (10).

\section{Materials and Methods}

Ex vivo PIPAC model. The experiments were performed using a standard ex vivo model with a eukaryotic cell line and bacteria strains. Therefore, no approval of the Institutional Review Board and no consent of the Local Board on Animal Care were required. Commercially available human serum was used (H4522, SigmaAldrich, St. Louis, USA). The ex vivo PIPAC model has been well established and previously described in many studies $(11,22)$. A commercially available hermetic plastic box with a total volume of
3.5 liter, mimicking the abdominal cavity, was used. In the center of the top cover of the plastic box, a $5 \mathrm{~mm}$ trocar (Kii ${ }^{\circledR}$ Balloon Blunt Tip System, Applied Medical, Rancho Santa Margarita, CA, USA) was placed. The nozzle of the MC was introduced into the trocar and the insufflator was connected. The plastic box was kept at constant room temperature of 27 degrees Celsius during the whole procedure. A sterile Petri dish was placed in the bottom corner of the box to collect aerosolized material for further analysis (Figure 1). The plastic box was then tightly sealed and a constant $\mathrm{CO}_{2}$ capnoperitoneum of $12 \mathrm{mmHg}$ (Olympus UHI-3, Olympus medical life science and industrial divisions, Olympus Australia, Notting Hill, Australia) was established for each single procedure. All experiments were repeated and independently performed four times.

Microcatheter (MK, PW-205V Olympus Surgical Technologies Europe, Hamburg, Germany).The MC consists of a connecting device with a pressure line connecting the shaft to the nozzle. The nozzle head has a small central opening. $10 \mathrm{ml}$ of each sample is delivered within a constant flow using a $10 \mathrm{ml}$ syringe and high manual pressure $(1 \mathrm{ml} / \mathrm{sec})$. The MC generates a polydisperse aerosol.

PIPAC of human serum. A total of $10 \mathrm{ml}$ of human serum (H4522, Sigma-Aldrich, St. Louis, USA) was used for PIPAC procedure. Samples before and after PIPAC were taken and dissolved 1:100 in phosphate buffer $(\mathrm{pH}=7.2)$. Then, SDS (Sodium dodecyl sulfate) sample buffer was added. The protein stability was analyzed by sodium dodecyl sulfate-polyacrylamide gel electrophoresis (SDSPAGE). The acrylamide concentration of the gel was $12 \%$. Gel was stained with Coomassie brilliant blue (Figure 2).

PIPAC of bacterial solution. Salmonella Enteritidis strain (isolate no. 327, (23)) and Escherichia coli strain PMC175 (commercially available) cultures were grown overnight at $37^{\circ} \mathrm{C}$ in LB broth. $3 \mathrm{ml}$ of culture was centrifuged $(2,700 \times \mathrm{g}$ for $3 \mathrm{~min})$, washed twice with phosphate buffer $(\mathrm{pH}=7.2)$ and resuspended in $10 \mathrm{ml}$ of phosphate buffer. PIPAC procedure was performed. Bacteria suspensions before and after the procedure were serially diluted, plated on LBagar and incubated overnight at $37^{\circ} \mathrm{C}$. Colony forming units (CFU) were counted (Figure 3).

PIPAC of macrophages. HD11 cells (HD11 cell line, Roslin Institute, Easter Bush, Midlothian, Scotland, UK) were maintained in RPMI 1640 supplemented with $10 \%$ fetal calf serum (FCS, Invitrogen, Carlsbad, CA, USA), $2 \mathrm{mM}$ L-glutamine, $1 \mathrm{mM}$ sodium pyruvate, 0.1 $\mathrm{mM}$ Non-Essential Amino Acids and antibiotics (Penicillin 0.06 $\mathrm{mg} / \mathrm{ml}$; Streptomycin $0.1 \mathrm{mg} / \mathrm{ml}$ ). The cells were grown in a humidified $5 \% \mathrm{CO}_{2}$ atmosphere. To evaluate cell population density (i.e. the total number of living cells in the culture) and cell viability (i.e. the percentage of living cells in the sample), Trypan Blue (TB) dye exclusion assay with a haemocytometer grid (Thoma neu chamber) was used. Cells were trypsinized, centrifuged and resuspended in $10 \mathrm{ml}$ of medium. Before and after PIPAC procedure $10 \mu \mathrm{l}$ of cell suspension were taken for TB assay. Measured viable cell count prior to PIPAC was defined as $100 \%$ (Figure 4).

Statistical analyses. Experiments were independently performed four times. The statistical analyses were performed with Sigma Plot 12 (Systat Software Inc., San Jose, CA, USA). The Kruskal-Wallis One Way Analysis of Variance on Ranks was used to compare independent groups. Descriptive statistics include mean, median and percentiles. 


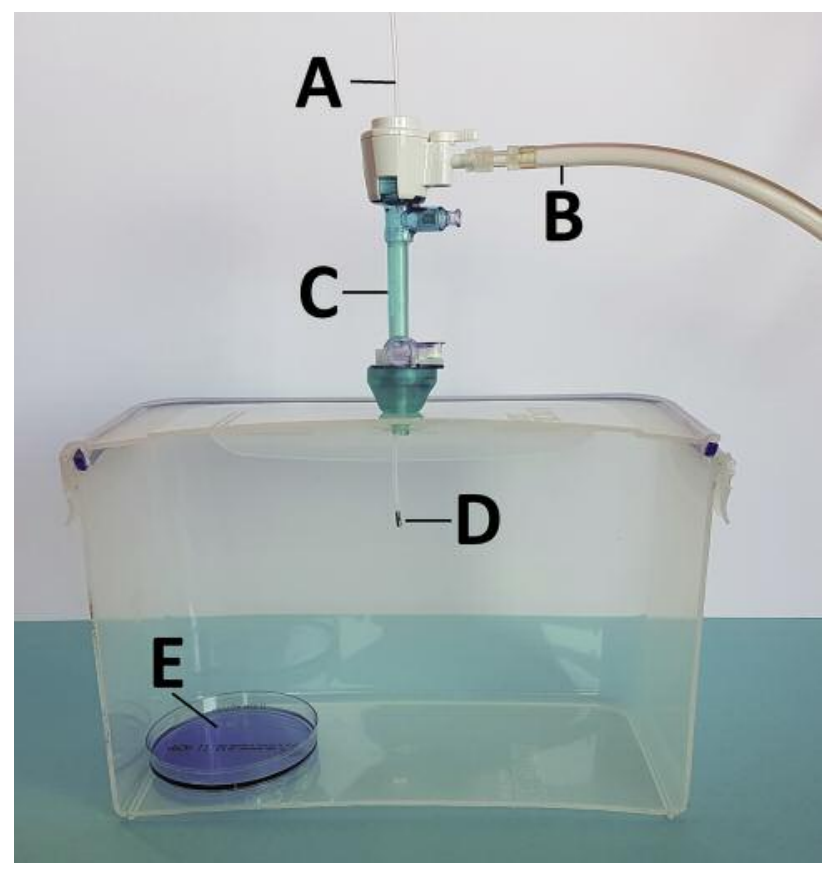

Figure 1. Laparoscopy-like ex vivo experiment. For better demonstration, the front wall of the plastic box (ex vivo PIPAC model) has been removed. Microcatheter was introduced through a 5-mm trocar and an insufflator was connected to the trocar as well. The petri dish is placed on the bottom corner of the box to collect the sprayed samples.

\section{Results}

Immediately after the start of the aerosol phase, the humidity reached $100 \%$ and remained constant during the entire procedure. At the end of the PIPAC procedure samples were retrieved from the Petri dish in the plastic box.

PIPAC of human plasma. Analysis of SDS-PAGE indicates no differences in human plasma (H4522, Sigma-Aldrich, St. Louis, MO, USA) protein stability prior to and after PIPAC. The molecular weight of particular protein bands was unaltered (Figure 2). The concentration of the protein solution showed no changes.

PIPAC of bacteria. Following PIPAC, the Escherichia coli (A) and Salmonella Enteritidis (B) solution showed similar viable bacterial concentrations like before PIPAC application. Mean concentrations in (A) prior to and after PIPAC were almost the same with values of $1.4 \times 10^{8} / \mathrm{ml}$ and $1.42 \times 10^{8} / \mathrm{ml}$, respectively. The mean concentrations in (B) showed values of $2.04 \times 10^{8} / \mathrm{ml}$ prior and $1.92 \times 10^{8} / \mathrm{ml}$ after PIPAC $(p>0.05)$, respectively. Thus, PIPAC application did not significantly change the bacteria concentrations in both (A) and (B) (no statistical significance, Figure 3).

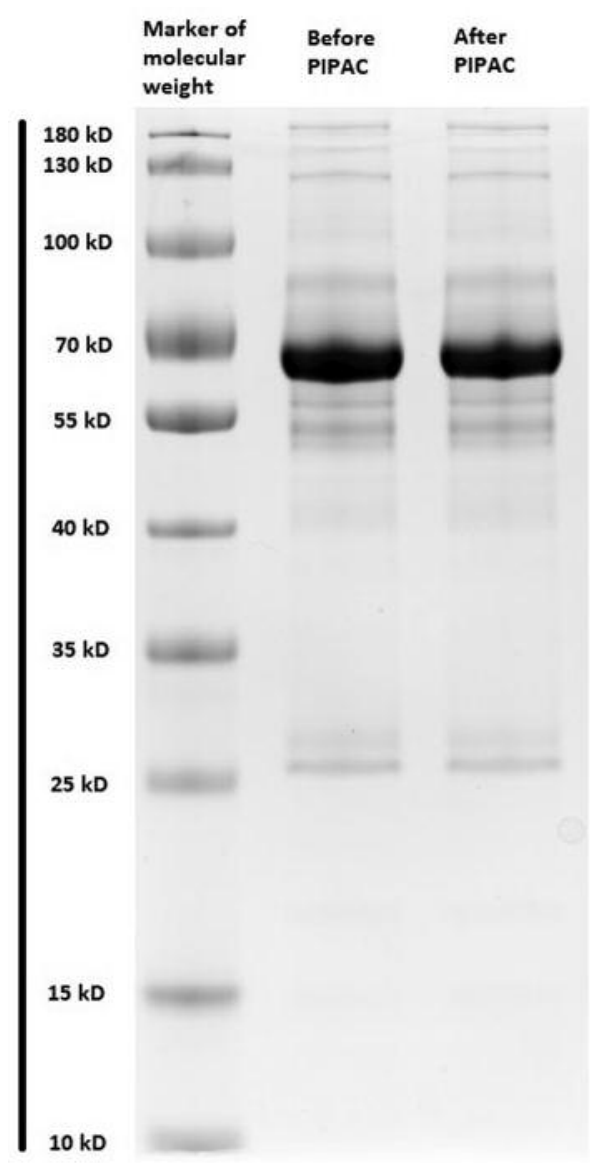

Figure 2. Coomassie brilliant blue-stained SDS-PAGE of blood serum prior to (middle column) and after PIPAC application (right column). The migration positions of protein standards are indicated on the left.

PIPAC of macrophages. The macrophage solution that received PIPAC (B) had a lower viable cell concentration than the solution without PIPAC (A). Mean cell concentration of the cell solution after PIPAC was $84 \%$ of the original solution $(p>0.05)$. Thus, the difference was statistically significant with $p<0.05$ (Figure 4 ).

\section{Discussion}

IPC delivered as a pressurized aerosol in form of PIPAC has been introduced as a new and innovative approach to improve the treatment of advanced, multi-resistant PM. This application has been reported to potentially overcome some of the limitations observed with conventional intraperitoneal chemotherapy with liquid solutions as in HIPEC. Special physical properties of PIPAC technology may significantly change the behavior and effects of applied substances.

Extension of current PIPAC therapy to application of more complex and larger particles or even cells requires further studies in the future. Particle behavior and their effects require 

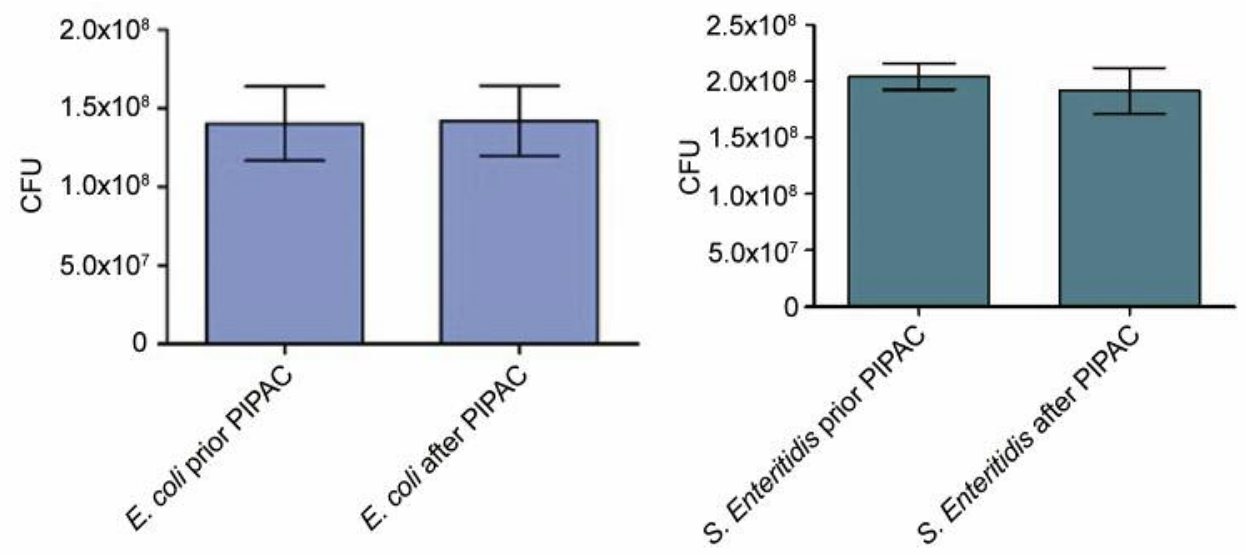

Figure 3. PIPAC of Escherichia coli (left) and Salmonella Enteritidis (right) data demonstrating bacterial colony forming unit (CFU) per milliliter prior to PIPAC and after PIPAC (Mean $\pm S D)$.

individual consideration following PIPAC application. This study gives important first insight and shows that the structural integrity and stability of some nano- and microparticles are not compromised by mechanical or physical stress during aerosol creation in PIPAC. While protein particles as well as bacteria withstand the procedure, macrophage cells show partial destruction. Yet, a large amount of these cells still survives the aerosol formation via microcatheter. Part of the destruction of the macrophage cells can be due to the $12 \mathrm{~mm} \mathrm{Hg}$ pressure during the experiment. The toxic effect of a $12 \mathrm{mmHg}$ capnoperitoneum has already been demonstrated in a similar recent ex vivo model (12). This pressure is part of the procedure and the creation of an intraperitoneal cavity and therefore cannot be avoided. While the initial focus in preclinical and clinical studies was on the effect of "classical" chemoagents like doxorubicin, oxaliplatin and cisplatin, the focus has recently shifted toward more complex applications (24), different molecules, antibodies like catumaxomab (18) and larger particles. Aerosol formation and transport onto peritoneal or even endoluminal surfaces might be highly relevant in future treatment for a wide range of diseases. The unique qualities and efficiency of PIPAC have been demonstrated in recent studies. With respect to the particular research interest on PIPAC, the introduction of new therapeutic agents for PIPAC application is very likely and may offer unexpected therapeutic benefits. Therefore, we believe our findings to be highly significant with respect to future therapeutic PIPAC applications.

\section{Conclusion}

Our data indicate that PIPAC of large and structurally sensitive particles is possible. Some particles' disintegration has to be expected with cells and larger structures $>5 \mu \mathrm{m}$. Overall, aerosol formation of complex particles via $\mathrm{MC}$ is feasible, yet requires further studies for clinical application.

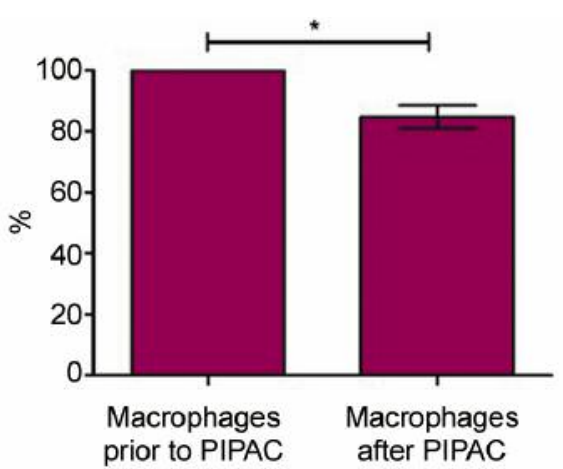

Figure 4. PIPAC of HD11 macrophages, viable cell count before and after PIPAC. Percent value of cell viability after PIPAC in comparison to prior measured cell viability, ${ }^{*} p<0.05$.

\section{Conflicts of Interest}

This study was funded by institutional funds. The Authors have no conflicts of interest or financial ties to disclose.

\section{References}

1 Sadeghi M, Arvieux C, Glehen O, Beaujard AC, Rivoire M, Baulieux J, Fontaumard E, Brachet A, Caillot JL, Faure JL, Porcheron J, Peix JL, François Y, Vignal J and Gilly FN: Peritoneal carcinomatosis from non-gynecologic malignancies: Results of the EVOCAPE 1 multicentric prospective study. Cancer 88: 358-363, 2000.

2 Dedrick RL, Myers CE, Bungay PM and DeVita VT Jr.: Pharmacokinetic rational for the peritoneal drug administration in the treatment of ovarian cancer. Cancer Treat Rep 62: 1-11, 1978.

3 Los G, Mutsaers PH, van der Vijgh WJ, Baldew GS, de Graaf PW and McVie JG: Direct diffusion of cis-diamminedichloroplatinum(II) in intraperitoneal rat tumor after intraperitoneal chemotherapy: a comparison with systemic chemotherapy. Cancer Res 49: 3380-3384, 1989. 
4 Jacquet P and Sugarbaker PH: Peritoneal-plasma barrier. Cancer Treat Res 82: 53-63, 1996.

5 Jain RK: Barriers to drug delivery in solid tumors. Sci Am 271: 58-65, 1994

6 Solaß W, Hetzel A, Nadiradze G, Sagynaliev E and Reymond MA: Description of a novel approach for intraperitoneal drug delivery and the related device. Surg Endosc (26): 1849-1855, 2012.

7 Khosrawipour T, Khosrawipour V and Giger-Pabst U: Pressurized intraperitoneal aerosol chemotherapy in patients suffering from peritoneal carcinomatosis of pancreatic adenocarcinoma. PLoS One 12(10): e0186709, 2017

8 Odendahl K, Solass W, Demtröder C, Giger-Pabst U, Zieren J, Tempfer C and Reymond MA: Quality of life of patients with end-stage peritoneal metastasis treated with pressurized intraperitoneal Aerosol Chemotherapy (PIPAC). Eur J Surg Oncol 41(10): 1379-1385, 2015.

9 Khosrawipour V, Khosrawipour T, Falkenstein TA, DiazCarballo D, Förster E, Osma A, Adamietz IA, Zieren J and Fakhrian K: Evaluating the effect of micropump ${ }^{\odot}$ position, internal pressure and doxorubicin dosage on efficacy of pressurized intraperitoneal aerosol chemotherapy (PIPAC) in an ex vivo model. Anticancer Res 36(9): 4595-4600, 2016.

10 Göhler D, Khosrawipour V, Khosrawipour T, Diaz-Carballo D, Falkenstein TA, Zieren J, Stintz M and Giger-Pabst U: Technical description of the microinjection pump $\left(\mathrm{MIP}^{\circledR}\right)$ and granulometric characterization of the aerosol applied for pressurized intraperitoneal aerosol chemotherapy (PIPAC). Surg Endosc 31(4): 1778-1784, 2017.

11 Khosrawipour V, Khosrawipour T, Hedayat-Pour Y, DiazCarballo D, Bellendorf A, Böse-Riberio H, Mücke R, Mohanaraja N, Adamitz IA and Fakhrian K: Effect of whole abdominal irradiation on penetration depth of doxorubicin in normal tissue after pressurized intraperitoneal aerosol chemotherapy (PIPAC) in a Post-mortem Swine Model. Anticancer Res 37(4): 1677-1680, 2017.

12 Khosrawipour V, Diaz-Carballo D, Acikelli AH, Khosrawipour T, Falkenstein TA, Wu D, Zieren J and Giger-Pabst U: Cytotoxic effect of different treatment parameters in pressurized intraperitoneal aerosol chemotherapy (PIPAC) on in vitro proliferation of human colonic cancer cells. World J Surg Oncol 15(1): 94, 2017

13 Khosrawipour V, Khosrawipour T, Hedayat-Pour Y, DiazCarballo D, Bellendorf A, Böse-Riberio H, Mücke R, Mohanaraja N, Adamitz IA and Fakhrian K: Effect of whole abdominal irradiation on penetration depth of doxorubicin in normal tissue after pressurized intraperitoneal aerosol chemotherapy (PIPAC) in a Post-mortem Swine Model. Anticancer Res 37(4): 1677-1680, 2017.

14 Khosrawipour V, Khosrawipour T, Kern AJ, Osma A, Kabakci B, Diaz-Carballo D, Förster E, Zieren J and Fakhrian K: Distribution pattern and penetration depth of doxorubicin after pressurized intraperitoneal aerosol chemotherapy (PIPAC) in a postmortem swine model. J Cancer Res Clin Oncol 142(11): 2275-2280, 2016.
15 Khosrawipour T, Wu D, Bellendorf A, Mohanaraja N, Karabay E, Diaz-Carballo D and Khosrawipour V: Feasibility of single tumorspot treatment in peritoneal carcinomatosisi via close range doxorubicin impaction in pressurized intraperitoneal aerosol chemotherapy (PIPAC). J Clin Exp Oncol 6(3): 2018. doi: 10.4172/2324-9110.1000187

16 Khosrawipour V, Khosrawipour T, Diaz-Carballo D, Förster E, Zieren $\mathrm{J}$ and Giger-Pabst U: Exploring the spatial drug distribution pattern of pressurized intraperitoneal aerosol chemotherapy (PIPAC). Ann Surg Oncol 23(4): 1220-1224, 2016.

17 Khosrawipour V, Mikolajczyk A, Schubert J and Khosrawipour T: Pressurized Intra-Peritoneal Aerosol Chemotherapy (PIPAC) via endoscopical microcatheter system. Anticancer Res 38(6): 3447-3452, 2018.

18 Linke R, Klein A and Seimetz D: Catumaxomab: Clinical development and future directions. MAbs 2(2): 129-136, 2010.

19 Harrison LE, Bryan M, Pliner L and Saunders T: Phase I trial of pegylated liposomal doxorubicin with hyperthermic intraperitoneal chemotherapy in patients undergoing cytoreduction for advanced intra-abdominal malignancy. Ann Surg Oncol 15(5): 1407-1413, 2008.

$20 \mathrm{Lu} \mathrm{Z}$, Tsai M, Lu D, Wang J, Wientjes MG and Au JLS: Tumorpenetrating microparticles for intraperitoneal therapy of ovarian cancer. J Pharmacol Exp Ther 327(3): 673-682, 2008.

21 Faradji A, Bohbot A, Schmitt-Goguel M, Roeslin N, Dumont S, Wiesel MJ, Lallot C, Eber M, Bartholeyns J and Poindron P: Phase I trial of intavenous infusion of ex vivo- activated autologous blood-derived macrophages in patients with nonsmall cell lung cancer: toxicity and immunomodulatory effects. Cancer Immunol Immunother 33(5): 319-326, 1991.

22 Khosrawipour V, Bellendorf A, Khosrawipour C, Hedayat-Pour Y, Diaz-Carballo D, Förster E, Mücke R, Kabakci B, Adamietz IA and Fakhrian K: Irradiation does not increase the penetration depth of doxorubicin in normal tissue after pressurized intraperitoneal aerosol chemotherapy (PIPAC) in an ex vivo model. In Vivo 30(5): 593-597, 2016.

23 Kisiela D, Laskowska A, Sapeta A, Kuczkowski M, Wieliczko A and Ugorski M: Functional characterization of the FimH adhesin from Salmonella enterica serovar Enteritidis. Microbiology 152(5): 1337-1346, 2006.

24 Kakchekeeva T, Demtröder C, Herath NI, Griffiths D, Torkington J, Solaß W, Dutreix $\mathrm{M}$ and Reymond MA: In vivo feasibility of electrostatic precipitation as an adjunct to pressurized intraperitoneal aerosol chemotherapy (ePIPAC). Ann Surg Oncol 23(5): 592-598, 2016.
Received June 10, 2018

Revised June 23, 2018

Accepted June 25, 2018 